\title{
Analysis of Power Quality Disturbances in Industry in the Centre Region of Portugal
}

\author{
Licínio Moreira $^{1,2}$, Sérgio Leitão ${ }^{2}$, Zita Vale ${ }^{3,4}$, João Galvão ${ }^{1,5}$, and Pedro Marques ${ }^{1}$ \\ ${ }^{1}$ School of Technology and Management, Polytechnic Institute of Leiria, \\ P-2411-901 Leiria, Portugal \\ ${ }^{2}$ UTAD-ECT Science and Technology School, \\ University of Trás-os-Montes and Alto Douro, Vila Real, Portugal \\ ${ }^{3}$ Department of Electrical Engineering, \\ Polytechnic Institute of Porto (ISEP/IPP), Porto, Portugal \\ ${ }^{4}$ GECAD (Knowledge Engineering and Decision Support Research Group), \\ Porto, Portugal \\ ${ }^{5}$ INESC Coimbra - Institute for Systems Engineering and Computers at Coimbra, \\ Coimbra, Portugal \\ \{licinio.moreira, jrgalvao, marques\} @ipleiria.pt, \\ sleitao@utad.pt, zav@dee.isep.ipp.pt
}

\begin{abstract}
Power quality issues have taken a more prominent role in power systems over the last years. These issues are of major concern for energy customers, primarily for customers with a widespread use of electronic devices in their manufacturing processes. Even though the quality of service is increasing, customers are becoming more demanding of the energy provider. This research aims to provide some industrial managers the technical support in deciding of investments in the mitigation of power quality disturbances, such as the use of less sensitive devices or the use of interface devices (UPS, DVR ...) In order to recommend an appropriate solution, the problem is characterized. The technical and economic influences of the PQ disturbances in the manufacturing processes are assessed resorting to power quality audits in the customer facilities. This research covered a significant number of facilities in several industrial activities.
\end{abstract}

Keywords: Power Quality, Audit, Voltage Sag, Voltage Swell, Interruption, Wiring.

\section{$1 \quad$ Introduction}

Power quality (PQ) problems are inevitability, even in state-of-the-art power networks. The current worldwide economic competitiveness requires the organizations to be stricter in delivery times, following the just-in-time production model, and the profit margins tend to become smaller. Thus, any interference in production may lead to failure in delivery, sometimes implying large economic (direct and indirect) losses [1], [2] and [3].

The constant modernization of the manufacturing processes is based on the widespread use of electronic equipment. These electronic devices have an increased 
sensitiveness to PQ disturbances and, at the same time are responsible for PQ degradation [4]. Several studies have been conducted to evaluate the costs of PQ problems for consumers. The assessment of an accurate value is nearly impossible; so all these studies are based on estimates. But all the studies point to losses valued in thousands of million Euros per year [5], [6] and [7]. In addition, the relevant studies point to the fact of investment made to minimize these disturbances is rather insignificant compared to the losses.

This research is centred in power quality audits conducted in several industrial facilities, such as plastic, moulds, wood, metallic construction and drywall manufacturing [8] and [9] in the centre of Portugal. Also some data from the quality of service reports issued by Portuguese energy regulator is used. The data is used to estimate losses (occurred and expected) and evaluate the economical feasibility of the use of mitigation techniques, including the use of uninterruptible power supplies (UPS), dynamic voltage restorers (DVR). The frequent contact with facility managers is used to encourage the option for devices that are less sensitive to short-duration PQ disturbances. Often, the PQ audits also deliver information used to the acting in the energy efficiency field.

\section{Contribution to the Collective Awareness Systems}

This work aims the rising of collective awareness on the mitigation of the problems arising from faulty power quality. Everyone in the electricity sector, from the generation to the consumption can and should be participative for the minimization of losses. The mission of the energy sector operators (generation, transmission and distribution) is to fulfil the requirements of the electricity consumers. The customers have become more aware and demand low-cost electricity of high reliability and quality, where the priorities are different for different customers. They are certainly no longer willing to accept their position as merely one parameter in a global optimisation [1].

On the other hand, the customers should take action, being proactive in the search for solutions that minimize the costs arising from PQ disturbances (mainly the ones with short duration) that are an inevitable. Standardization (both on supply and demand sides) plays an important role defining PQ parameters that are acceptable for the satisfaction of electricity consumers, but also defining standards for end-use equipments tolerance and interface devices. Fig. 1 resumes the actuation levels and strategies that could lead to a decrease in the magnitude of PQ events.

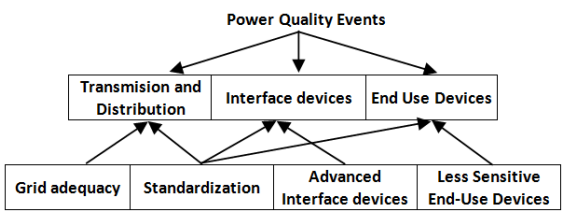

Fig. 1. Different levels of the electricity sector and actuation strategies 


\section{Data Collected from Distribution Network Operator}

Every year, the operators of the transmission and distribution (T\&D) networks are obliged to prepare and submit to the energy sector regulator reports stating the technical and commercial quality of the service provided. The technical quality of service is related to the analysis of the continuity of service, through the number and duration of supply interruptions, and the quality of the voltage wave (evaluation of its frequency values, amplitude, harmonic distortion, imbalance and others) [10].

To estimate the average annual number of voltage sags in each industrial facility, the values found in the quality of service report for medium voltage (MV) buses with permanent monitoring can be helpful, combined with the data collected in PQ audits. Table 1 shows the registered events categorized by time and amplitude.

Table 1. Average number of voltage sags in MV buses of the distribution network in 2012

\begin{tabular}{|c|c|c|c|c|c|c|c|}
\hline \multirow{2}{*}{$\begin{array}{c}\text { Retained } \\
\text { Voltage }\left(\% \mathbf{U}_{\mathrm{c}}\right)\end{array}$} & \multicolumn{6}{|c|}{ Number / Duration (seconds) } & \multirow[b]{2}{*}{$\%$ of events } \\
\hline & ]0.01;0.1] & ]0.1;0.25] & ] $0.25 ; 0.5]$ & ]0.5;1] & ] $1<; 3]$ & ]3;20] & \\
\hline $80 \%<\mathrm{U}<90 \%$ & 26.10 & 11.59 & 3.30 & 5.85 & 2.08 & 0.16 & 53.6 \\
\hline $70 \%<\mathrm{U}<\mathbf{8 0} \%$ & 6.38 & 5.49 & 1.99 & 2.10 & 1.19 & 0.05 & 18.8 \\
\hline $60 \%<\mathrm{U}<70 \%$ & 3.74 & 2.27 & 1.78 & 1.24 & 0.94 & 0.14 & 11.1 \\
\hline $50 \%<\mathrm{U}<60 \%$ & 0.64 & 1.53 & 1.72 & 0.78 & 0.59 & 0.03 & 5.8 \\
\hline $40 \%<\mathrm{U}<50 \%$ & 0.33 & 0.81 & 1.05 & 0.33 & 0.78 & & 3.6 \\
\hline $30 \%<\mathrm{U}<40 \%$ & 0.36 & 0.89 & 0.75 & 0.48 & 0.30 & & 3.0 \\
\hline $20 \%<\mathrm{U}<30 \%$ & 0.08 & 0.30 & 0.72 & 0.36 & 0.11 & 0.08 & 1.8 \\
\hline $10 \%<\mathrm{U}<20 \%$ & 0.11 & 0.22 & 0.78 & 0.25 & & & 1.5 \\
\hline $1 \%<\mathrm{U}<10 \%$ & 0.03 & 0.11 & 0.22 & 0.19 & 0.11 & & 0.7 \\
\hline$\%$ of events & 41.3 & 25.4 & 13.5 & 12.7 & 6.7 & 0.5 & \\
\hline
\end{tabular}

The total number of sags recorded was 3843 over 42 buses. This results in an average of 91.5 sags per bus per year in 2012. This record is $15 \%$ lower than the one recorded in 2011. The shadowed cells on Table 1 represent the events that are under the lower limits of the ITIC curve, and are therefore likely to cause malfunction on electronic devices, such as computer numerical control (CNC) machines, widely used in manufacturing processes. The fraction of the occurrences under the ITIC curve is $18.8 \%$, representing approximately 17 sags per year that can cause equipment malfunction.

This national average value is very similar to the value recorded in the substations located in the Leiria area, validated by the records of the distribution network operator and the data collected in the PQ audits conducted in this research.

\section{$4 \quad$ Power Quality Audits}

The referred several audits were performed using two Hioki Power Quality Analysers 3196. The PQ analysers were installed in low voltage buses with settings that are in accordance with EN 50160. These devices allow the continuous monitoring of electrical parameters and the recording of averaged values and the recording of transient phenomena, such as interruptions, voltage sags, swells and other. 
Nearly all data collected was compliant with the norm. The only exception was registered on the $19^{\text {th }}$ of January, 2013, when a gale occurred in Portugal, leading to the destruction of several power distribution network infrastructures, causing service interruptions that lasted for several days in some areas of the centre of Portugal. One can conclude that the values required by the norm are easily fulfilled (excluding acts of god) by the distribution operator, since the norm only applies to average voltage values of 10 minutes. Nevertheless, even when the quality of service complies with the norm, some disturbances which are detected are responsible for equipment malfunction and the disruption of manufacturing processes [11].

\subsection{Voltage Sags}

The voltage sags and swells recorded during a monitoring campaign in a metallic construction site, with several CNC machines (one week period) are represented in Fig. 2. These events are plotted in the ITIC curve, which defines the expected tolerance of electronic equipment to voltage variation events. Events plotted in the upper shaded area (swells) are dangerous for the equipment, susceptible of causing damages to it, while the events plotted in the lower shaded area may cause malfunction of the devices, but shouldn't be destructive. Any event in the non shaded area shouldn't interfere with normal function of the device.

The plot shows the occurrence of six voltage sags, with three of them under the tolerance limits defined in the ITIC curve.

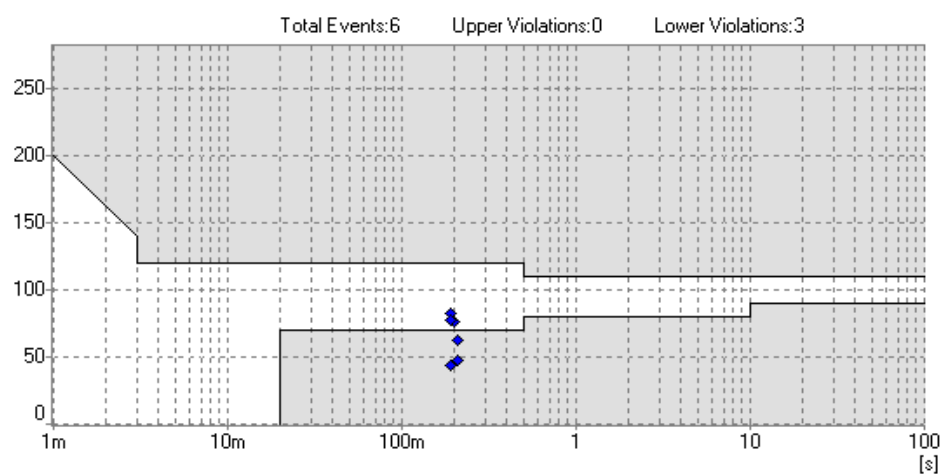

Fig. 2. Voltage sags and swells recorded over a week period (from the $14^{\text {th }}$ to the $21^{\text {st }}$ of March, 2013) and plotted over the ITIC curve

The average voltage values with $10 \mathrm{~ms}$ sampling time during a voltage sag is represented in Fig. 3. The voltage retained is $109 \mathrm{~V}$ and the duration is $201 \mathrm{~ms}$.

The events recorded by the energy analyser were compared with the record of manufacturing process disturbances. The sag represented in Fig. 3 is responsible for a CNC machine malfunction causing the delay of the piece production of several hours. The CNC needed to be reprogrammed before continuing the piece machining. 


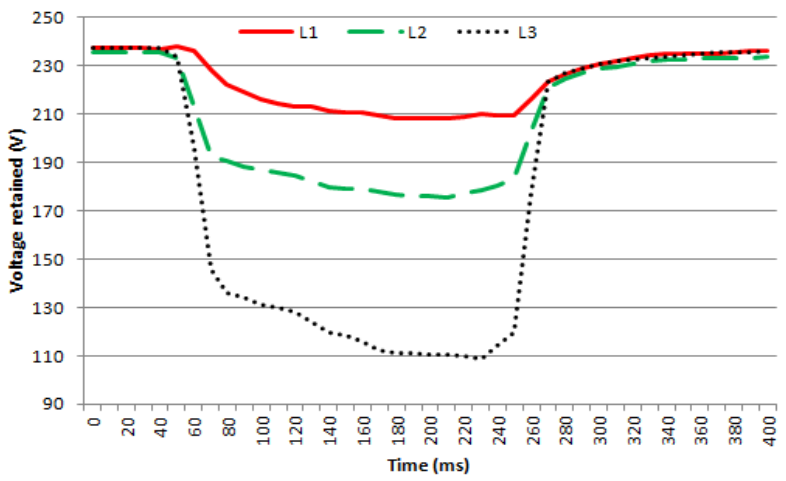

Fig. 3. Voltage sag recorded on the $18^{\text {th }}$ of March, 2013

In some cases reported by facility managers, some malfunctions due to voltage sags or micro-interruptions cause damages to tools and / or machined piece. This can happen if the tool is performing a high speed operation and becomes uncontrolled due to the power failure in the controller.

\subsection{Voltage Swells}

Voltage swells are also transient phenomena susceptible of causing damage. These occur less frequently, but in some severe cases are more likely to cause direct damages on electrical equipment.

During the monitoring campaigns made, no damage could be directly related to the occurrence of a voltage swell, but it is widely known that voltage swells contribute to the lifetime shortening of electrical devices.

In Fig. 4, the most severe voltage swell (both in amplitude and duration) is plotted. In phase L3, the voltage reached $277.7 \mathrm{~V}$ (20.7\% over rated voltage) and the duration was of about 20 seconds.

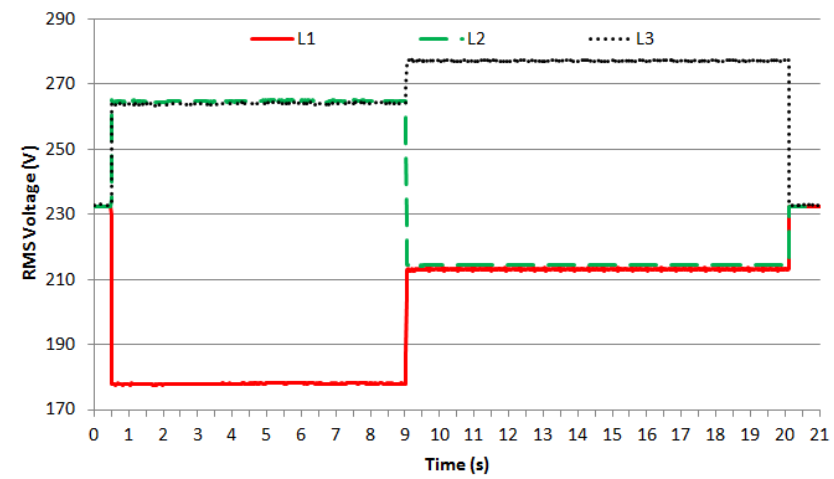

Fig. 4. Voltage swell recorded on the $15^{\text {th }}$ of February, 2013 


\subsection{Wiring}

The selection of proper wiring and protective devices is imperative for the operation of an electrical installation and the proper functioning of end use devices. Also, an incorrect installation, from the placement of the components to the correct tightening, can lead to the occurrence of problems.

During the conducted audits, several situations were detected, some before the destruction of equipment, others detected after the equipment failure because of improper tightening.

One example is the destruction of the connector in several ballasts in an industrial facility. The improper connection, combined with the expected heating of the ballast and lamp, led to an overheating and destruction of the terminals of the ballast.

With the use of a thermal camera (Fluke Ti45 Flexcam $^{\mathrm{TM}}$ ), during a normal assessment, a difference of temperature was detected in a set of cables connecting the power transformer (in the customer substation) to the main electrical switchboard. The connection was made using three cables (H1XV-R 1x300 mm²) for each phase and for the neutral. The thermal image for each phase is shown in Fig. 5. It is easily found that the current distribution by parallel cables in every phase is unequal.

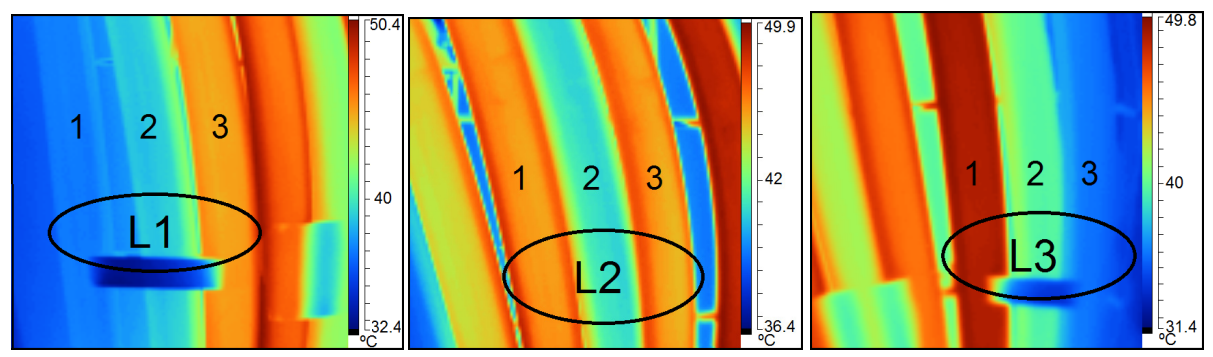

Fig. 5. Thermal imaging of electric cables

The current in each cable was measured and registered. These values are presented in Table 2, such as the surface temperature of the cables.

Table 2. Current and surface temperature in cables between transformer and the main switchboard

\begin{tabular}{|c|c|c|c|c|c|c|}
\cline { 2 - 7 } \multicolumn{1}{c|}{} & \multicolumn{2}{c|}{ Phase L1 } & \multicolumn{2}{c|}{ Phase L2 } & \multicolumn{2}{c|}{ Phase L3 } \\
\cline { 2 - 7 } \multicolumn{1}{c|}{} & Current & Temp. & Current & Temp. & Current & Temp. \\
\hline Cable 1 & $236 \mathrm{~A}$ & $36^{\circ} \mathrm{C}$ & $412 \mathrm{~A}$ & $38^{\circ} \mathrm{C}$ & $483 \mathrm{~A}$ & $46^{\circ} \mathrm{C}$ \\
\hline Cable 2 & $198 \mathrm{~A}$ & $48^{\circ} \mathrm{C}$ & $201 \mathrm{~A}$ & $42^{\circ} \mathrm{C}$ & $203 \mathrm{~A}$ & $46^{\circ} \mathrm{C}$ \\
\hline Cable 3 & $374 \mathrm{~A}$ & $49^{\circ} \mathrm{C}$ & $345 \mathrm{~A}$ & $39{ }^{\circ} \mathrm{C}$ & $181 \mathrm{~A}$ & $37{ }^{\circ} \mathrm{C}$ \\
\hline Phase rms current & $\mathbf{7 7 8 ~ A}$ & - & $\mathbf{7 9 8 ~ A}$ & - & $\mathbf{8 6 1 ~ A}$ & - \\
\hline
\end{tabular}


The values show the expected imbalance of currents, of which the currents in phase L3stand out. In this phase, the most heavily loaded cable conducts 2.67 times the current of the least loaded cable. One can also easily conclude that the sum of the current in the three cables for each phase is greater than the rms current for the phase. For example, in phase L2, the algebraic sum of the current in the three cables is $958 \mathrm{~A}$ and the rms current is only of $798 \mathrm{~A}$.

Considering that the admissible current of the conductors is of approximately $580 \mathrm{~A}$, no cable is overloaded. Also, the temperature of every cable is within acceptable limits. The problem hasn't reached critical values, because the transformer (with $1600 \mathrm{kVA}$ rated power) is underload, presenting an average load of $650 \mathrm{kVA}$ and a maximum load of about $800 \mathrm{kVA}$. In the case of a load increase, the cables would suffer a lifetime reduction and, in an extreme event, could trigger a fire.

This imbalance is caused by an incorrect geometric distribution of the cables on the cable tray. The cables are arranged vertically with the sequence shown Fig. 7 (top). This arrangement promotes the increase of mutual inductances in some cables [12] and [13]. It was recommended the change of the arrangement for the one portrayed on Fig. 7 (bottom). The trefoil formation would represent a better solution, but it would be harder to implement, implying the enlargement of holes in a wall and the reinstallation (or even replacement) of cable trays.

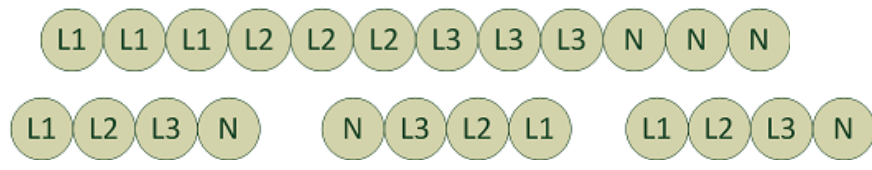

Fig. 6. Present arrangement (top) and proposed re-arrangement (bottom) of cables connecting the transformer and the main switchboard

\section{Conclusions}

This project has identified several issues related with power quality disturbances that effectively affected production processes, mainly in activity sectors with intensive use of $\mathrm{CNC}$ systems, whose methods of quality control are very strict in the manufacturing of steel (in the order of microns). In addition, some issues that could potentially become a problem were detected and solutions were proposed in order to take action anticipating possible damages.

The degradation of power quality can be a trouble resulting in large financial losses. With the increasing competitiveness of world economy, but also with the low financial capability, particularly of most of the Portuguese companies, every investment in power quality improvement must be analysed wisely. The implementation of a monitoring and recording smart system, where the PQ disturbances and their consequences are registered could support the taking of better, informed and sustainability-aware decisions. The linkage of objects, people and knowledge promotes the network effect for the cooperative awareness. 


\section{References}

1. Bollen, M.H.J.: What is power quality? Electric Power Systems Research 66(1), 5-14 (2003), doi:10.1016/S0378-7796(03)00067-1, ISSN 0378-7796

2. Bayliss, C.R., Hardy, B.J.: Power Quality - Voltage Disturbances. In: Bayliss, C.R., Hardy, B.J. (eds.) Transmission and Distribution Electrical Engineering, 4th edn., Newnes, Oxford, ch. 25, pp. 1013-1026 (2012), doi:10.1016/B978-0-08-096912-1.00025-3, ISBN 9780080969121

3. Math, H.J.: Bollen, Understanding Power Quality Problems - Voltage Sags and Interruptions. Wiley-Interscience - IEEE Press, New York (2000)

4. Vairamohan, B., Komatsu, W., Galassi, M., Monteiro, T.C., de Oliveira, M.A., Ahn, S.U., Matakas Jr., L., Marafão, F.P., Bormio Jr., E., de Camargo, J., McGranaghan, M.F., Jardini, J.A.: Technology assessment for power quality mitigation devices - Micro-DVR case study. Electric Power Systems Research 81(6), 1215-1226 (2011), doi:10.1016/j.epsr.2011.01.014, ISSN 0378-7796

5. Chapman, D.: Costs of Poor Power Quality. Power Quality Application Guide - Copper Development Association (March 2001)

6. Targosz, R., Manson, J.: Pan-European Power Quality Survey - A study of the impact of power quality on electrical energy critical industrial sectors. In: Proceedings of the 9th Conference on Electrical Power Quality and Utilisation, Barcelona, Spain, October 9-11 (2007)

7. Coll-Mayor, D., Pardo, J., Perez-Donsion, M.: Methodology based on the value of lost load for evaluating economical losses due to disturbances in the power quality. Energy Policy 50, 407-418 (2012), doi:10.1016/j.enpol.2012.07.036, ISSN 0301-4215

8. Moreira, L., Leitão, S., Vale, Z.: Power Quality problems in the mould Industry. In: 11th Spanish Portuguese Congress on Electrical Engineering (11 CHLIE), Zaragoza, July 1-4 (2009)

9. [IYCE] Galvão, J., Moreira, L., Leitão, S., Silva, E., Neto, M.: Sustainable Energy for Plastic Industry Plant, Proceedings of 4th International Youth Conference on Energy, IYCE/IEEE, Siófok, Hungary (June 2013), doi: 10.1109/IYCE.2013.6604193

10. Entidade Reguladora dos Serviços Energéticos, Quality of Service in the Electric Sector 2012, Lisboa (October 2013)

11. Martinez, J.A., Martin-Arnedo, J.: Voltage sag studies in distribution Networks-part I: system modeling. IEEE Transactions on Power Delivery 21(3), 1670-1678 (2006), doi:10.1109/TPWRD.2006.874113

12. Du, P.Y., Wang, X.H.: Electrical and Thermal Analyses of Parallel Single-Conductor Cable Installations. IEEE Transactions on Industry Applications 46(4), 1534-1540 (2010), doi:10.1109/TIA.2010.2049819

13. Du, Y., Burnett, J.: Current distribution in single-core cables connected in parallel. Generation, Transmission and Distribution, IEE Proceedings 148(5), 406-412 (2001), doi:10.1049/ip-gtd:20010430 